\title{
Implementation of Digital Literacy toward Pandemic Situation
}

\author{
Puji Hariati \\ Amik Medicom, Indonesia \\ zeenasution@gmail.com
}

\begin{abstract}
This paper aims to describe the level of students' digital literacy in their study since pandemic situation. It is very important to know because it gives the answer of education's challenging faced covid19 situation for the students' safe and comfortable. This research is survey research to describe the implementation of digital literacy through level of digital literacy as challenging pandemic situation. Data collection techniques using the instrument in the form of a questionnaire. The four concept was constructed referred to Bawden (2008) such as basic literacy skills (reading and writing), background information knowledge (intellectual level), skills in the field of ICT, and attitudes and perspectives. This needs to be known to identify how far digital literacy was important for the students in their studying since Covid- 19 situation. This research involved 20 respondents who always use digital literacy in their study. The data was collected from the distribution of digital literacy questionnaire instruments for the students, then the data was describing through percentage to know how the students' level of digital legacy when there are teaching learning process. The findings indicate that respondents have a high level of digital literacy. In the aspect of basic digital literacy skills, all respondents were able to connect to the platform to take part in online learning, and were able to use worksheet technology to write assignment articles according to the provisions. In the aspect of background information knowledge, almost all respondents were able to find learning supplements in the form of reference articles and find their relevance based on the abstracts of the articles. In the main aspects of digital literacy, most respondents are able to cite the relevant sections to compile assignment articles, and are able to compare the contents of several reference articles. On the aspects of attitudes and perspectives of information users, all respondents are able to write citations and compile a bibliography for reference articles referred to.
\end{abstract}

Keywords

digital literacy; level of digital literacy; students' teaching

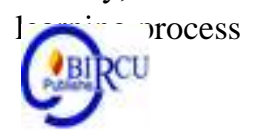

\section{Introduction}

The coronavirus disease (COVID-19) pandemic has caused an unprecedented crisis in all areas. In the field of education, this emergency has led to the massive closure of face-toface activities of educational institutions in more than 190 countries in order to prevent the spread of the virus and mitigate its impact. According to data from the United Nations Educational, Scientific and Cultural Organization (UNESCO), by mid-May 2020, more than 1.2 billion students at all levels of education worldwide had stopped having face-to-face classes. It means that the recent outbreak of the Coronavirus pandemic increased the gaps in the education sector globally.

The problems posed by the Covid-19 pandemic which have become a global problem have the potential to trigger a new social order or reconstruction. Thus it is necessary to have close communication between stakeholders and the community in responding to the problems 
mentioned above. Then it takes a study that kredibility has the expertise to research this phenomenon, especially in the Mandailing Natal area. This needs to be done in communicating so that it is known the effectiveness of advertisements in print media during pendemicovid 19. (Bara et al, 2021)

To address the challenges and harness the opportunities offered by digital technologies during this crisis, participants shared a concern to recognize and protect digital rights in particular around the areas of privacy and inclusion. Hyun and Joon (2014) state that application of digital technologies must be responsive to and inclusive of all members of population and close the digital divide. The last question reaffirmed the increased demand for digital technologies in response to the COVID-19 pandemic and stressed how it is imperative for local and regional governments to prioritize digitalization.

Shopova (2014) notes that digital literacy is chosen as the skills and technological knowledge for individuals to develop long-term learning activities and contribute well to society since to the COVID-19 pandemic. It is a key skill in education today. It includes various types of literacy, such as information literacy, computer literacy, media literacy, communication literacy, visual literacy, and technological literacy. This digital can help young people to benefit from information sources connected with digital technology and prepare themselves to face the challenges of today's technology. Not only building knowledge access skills, but digital literacy also builds critical thinking skills in the use of digital technology. Success in building digital literacy skills is one indicator of achievement in education (Keskin, et.al, 2015). Thus, it can be understood that this digital can be interpreted as the ability of individuals to apply functional skills to digital devices so they can find and choose information, think critically, be creative, collaborate with others, communicate effectively, and still pay attention to electronic security.

Digital literacy is important to apply all the subjects of students' learning. The application of digital literacy in teaching learning process provides opportunities for interaction, literacy of interesting reading sources, diverse material references, communication, and problem-solving. Santoso, dan Lestari, (2019) state that digital literacy can help students understand their material of learning. Through digital literacy. Seeing the importance of digital literacy in teaching learning process, the Ministry of Education and Culture in collaboration with the Ministry of Communications and Information is actively promoting digital literacy in the community, such as digital literacy activities. This is also supported by McLoughlin (2011) asserts that showing that digital literacy can develop one's knowledge, encourage curiosity and creativity, most students have good skills in using social networking, e-mail or Skype, surfing the internet as a community in cyberspace. Therefore, this digital era requires students to be able to follow the development of science and technology so that learning is presented following the times and the needs of students.

Based on these explanations, it can be describe the level of students' digital literacy in their study since pandemic situation. It is very important to know because it gives the answer of education's challenging faced covid-19 situation for the students' safe and comfortable. 


\section{Review of Literature}

\subsection{Definition of Digital Literacy}

The thoughtful adoption of digital learning modes in higher education supports the development of digitally literate students, who can operate comfortably and creatively in technology-enabled environments in all aspects of their lives. Murray and Perez (2014) state that awareness, attitude and ability of individuals to appropriately use digital tools and facilities to identify, access, manage, integrate, evaluate, analyze and synthesize digital resources, construct new knowledge, create media expressions, and communicate with others, in the context of specific life situations, in order to enable constructive social action; and to reflect upon this process. It means that through digital literacy, the knowledge and skills can be structured dimensionally in five "components of digital competence": information and data literacy, communication and collaboration, digital content creation, safety, and problem solving. Within these categories are specific sub-competences, which can be measured across eight levels of proficiency, ranging from "foundation" to "highly specialized."

Sense (2009) defines digital literacy as the ability to understand and use information in various formats (text, images, audio, video, and animation) which taken from various sources presented through electronic devices. Meanwhile, McLoughlin, (2011) states that digital literacy is defined as the use of technology to find information, use that information as thought input, and disseminate enriched information through digital platforms. Thus, digital literacy also involves the ability to understand, analyze, provide an assessment of the various information received, and evaluate that information.

From the explanation previously, it can described that digital literacy as the ability to utilize technology, interpret and understand, and assess the credibility of information contained in digital content. It means that digital literacy as the ability a person has to be able to use a computer and access the content in it properly and optimally to challenge pandemic situation.

\subsection{Level of Digital Literacy}

Bawden (2008) states that there are four level of affecting digital literacy such as basic literacy skills (reading and writing), background information knowledge (intellectual level), skills in the field of ICT, and attitudes and perspectives. Through these factors, it can be known that digital literacy competencies have a significant role in online learning activities. As with other competencies, digital literacy skills do not appear instantly, but are influenced and arranged by many aspects.

\section{a. Basic Literacy Skills}

Basic literacy skills include the ability to read, write, understand symbols, and calculate numbers. In the context of online learning, this ability can be in the form of the ability to understand terms and symbols (icons) used in software, create a file containing text and images, and the ability to share these files via digital platforms.

\section{b. Background Information Knowledge}

Background information knowledge is the ability to use existing knowledge to explore new information in order to enrich the knowledge already owned. In the context of online learning, background information can be interpreted as the ability to find information online via search engines, and select search results to match the online learning context that is being followed. 


\section{c. ICT Skills}

ICT field skills are creating / compiling digital content. These skills are the main competencies in the field of digital literacy, and involve the ability to assemble information or knowledge. In the context of online learning, this ability related to the ability to compile a document or article of a scientific nature as a learning output that is followed.

\section{d. Attitudes and Perspectives of Information Users}

The attitudes and perspectives of information users are behavior related to how to use digital information, and how to communicate content that contains information from other sources. In the context of online learning, this aspect can be in the form of the ability to include quotes from other information sources through citation rules and bibliography compilation.

\section{Research Methods}

This research is survey research to describe the implementation of digital literacy trough level of digital literacy as challenging pandemic situation. Data collection techniques using the instrument in the form of a questionnaire. The four concept was constructed referred to Bawden (2008) such as basic literacy skills (reading and writing), background information knowledge (intellectual level), skills in the field of ICT, and attitudes and perspectives. This needs to be known to identify how far digital literacy was important for the students in their studying since Covid- 19 situation. This research involved 20 respondents who always use digital literacy in their study. The researcher uses stratified sampling and random in this study to ensure that each member of the population has the same possibility to be chosen as part of the sample. After the data is collected from the distribution of digital literacy questionnaire instruments for the students, then the data was describing through percentage to know how the students' level of digital legacy when there are teaching learning process.

\section{Discussion}

To know the implementation of digital literacy for the students in their study during covid-19 pandemics, the result of students' questionnaire can be described as following.

\subsection{Basic Digital Literacy Skills}

Basic literacy skills include the ability to read, write, understand symbols, and calculate numbers. In the context of online learning, this ability can be in the form of the ability to understand terms and symbols (icons) used in the software, create a file which contains text and images, and the ability to share these files via digital platforms. In this study, this ability was measured through two parameters, (i) the ability to connect to a learning platform, and (ii) the ability to write assignments in the form of a systematic Microsoft Word file. Table 1 shows the measurement results of basic digital literacy skills. 
Table 1. Basic Digital Literacy Skills

\begin{tabular}{lcc}
\hline Measured Aspect & Majority Outcomes & Percentage (\%) \\
\hline $\begin{array}{l}\text { The ability to connect on the online } \\
\text { learning platform at a predefined time. }\end{array}$ & High & $100 \%$ \\
\hline $\begin{array}{l}\text { The ability to write assignments in the } \\
\text { form of Microsoft Word files containing }\end{array}$ & High & $100 \%$ \\
text and graphics, as well as a neat writing & & \\
format connected to the online learning & & \\
platform at a predetermined time. &
\end{tabular}

Based on the Table 1, it showed all respondents were able to connect to the platform to take part in online learning, and be actively involved during learning virtually, and were able to use the camera and microphone features to communicate during learning. Respondents are also able to use worksheet technology to write assignment articles, which contain text and graphics. Respondents are also able to submit the assignment articles online on a predetermined channel, and in a format in accordance with the provisions.

\subsection{Background of Information Knowledge}

Background information knowledge is the ability to use existing knowledge to explore new information in order to enrich existing knowledge. In the context of online learning, background information is reflected in the ability to search for information via the internet and select search results to suit the learning context being followed. In this study, this ability was measured through two parameters, namely: (i) determining 'search keywords' in search engine, and (ii) being able to make a selection to get reference articles that are relevant to the online learning that is being followed. Table 3 below shows the results of the measurement of background knowledge information.

Table 2. Background Knowledge Information

\begin{tabular}{l|c|c}
\hline \multicolumn{1}{c|}{ Measured Aspect } & Majority Outcomes & Percentage (\%) \\
\hline $\begin{array}{l}\text { Able to define "search keywords" on search } \\
\text { engines to find relevant reference articles }\end{array}$ & High & $94,2 \%$ \\
\hline $\begin{array}{l}\text { Be able to determine whether a reference } \\
\text { article is found to be relevant or not, based } \\
\text { on the abstract of the article }\end{array}$ & High & $92,1 \%$ \\
\hline
\end{tabular}

Based on the Table 2, almost all respondents were able to find learning supplements in the form of reference articles. The reference articles were accessed through search engines, and almost all respondents were able to determine the right keywords so they were able to access the article. Furthermore, respondents are also able to identify relevant search results based on the abstract of the reference article.

\subsection{ICT Skills}

Skills in the ICT field are creating or compiling digital content by using the ability to assemble information or knowledge. In the context of online learning, this ability is related to the ability to compile a document or article of a scientific nature as a learning output that is followed. In this study, these skills were measured through two parameters, namely: (i) ability to cite information, and (ii) ability to compare information from two reference article sources. The following table shows the results of measuring the main competencies of digital literacy. 
Table 3. ITC Skills

\begin{tabular}{l|c|c}
\hline Measured Aspect & Majority Outcomes & Percentage (\%) \\
\hline $\begin{array}{l}\text { Being able to retrieve information from } \\
\text { reference articles and quote it to enrich the } \\
\text { assignment made. }\end{array}$ & High & $88,2 \%$ \\
\hline $\begin{array}{l}\text { Be able to compare two reference articles } \\
\text { and mention the different methods used, } \\
\text { along with their advantages and } \\
\text { disadvantages }\end{array}$ & High & $84,3 \%$ \\
\hline
\end{tabular}

The results showed that most respondents could cite the relevant sections to compile the assignment article. In addition, most respondents also had more than one reference article, and were able to compare the two articles.

\subsection{Attitudes and Perspectives of Information Users}

The attitudes and perspectives of information users are behaviors related to the procedures for the use of digital information. In the context of online learning, this aspect can be in the form of the ability to include sources of citations from other sources through citation rules and preparation of bibliography. In this study, this attitude was measured through two parameters, namely: (i) how to do citations, and (ii) how to compile a bibliography. Table 4 below shows the results of measuring the main competencies of digital literacy.

Table 4. Attitudes and Perspectives of Information Users

\begin{tabular}{|l|c|c|}
\hline \multicolumn{1}{|c|}{ Measured Aspect } & Majority Outcomes & Percentage (\%) \\
\hline $\begin{array}{l}\text { Knowing how to cite the part of the } \\
\text { journal that is referred to }\end{array}$ & High & $92,4 \%$ \\
\hline $\begin{array}{l}\text { Knowing how to add the referred journal } \\
\text { to the bibliography. }\end{array}$ & High & $93,2 \%$ \\
\hline
\end{tabular}

The results showed that almost all respondents had a good attitude in using information. This is indicated by the respondent's ability to write citations to the reference articles being referred to. One of the supporters of this attitude is the existence of a culture of academic ethics that must be adhered to by the entire academic community of the school. This attitude illustrates that the respondent has the responsibility for the content of information from other parties.

\section{Conclusion}

The change in this method is quite drastic and the only options available are virtual lectures, where face-to-face classes are replaced by face-to-face via virtual and involve digital technology. In a higher education environment, lecturers and students are required to hold virtual classes and meetings on one of the platforms and software mentioned above. This preparation is carried out in a very short time and without formal socialization. One of the key factors in changing the lecture method is the competence of lecturers and students in using technology to manage the distance learning process. This capability is part of digital literacy, which can be interpreted as the ability to use and manage technology, information and communication systems.

Based on the result and discussion of the study, it can be described that respondents have a high level of digital literacy when measured using the Bowden's Concept. In the 
aspect of basic digital literacy skills, all respondents were able to connect to the platform to take part in online learning, and were able to use worksheet technology to write assignment articles according to the provisions. In the aspect of background information knowledge, almost all respondents were able to find learning supplements in the form of reference articles and find their relevance based on the abstracts of the articles. In the main aspects of digital literacy, most respondents are able to cite the relevant sections to compile assignment articles, and are able to compare the contents of several reference articles. On the aspects of attitudes and perspectives of information users, all respondents are able to write citations and compile a bibliography for reference articles referred to.

\section{References}

Bara, A. et al. (2021). The Effectiveness of Advertising Marketing in Print Media during the Covid 19 Pandemic in the Mandailing Natal Region. Budapest International Research and Critics Institute-Journal (BIRCI-Journal). P. 879-886

Bawden, D. (2008). Origins and concepts of digital literacy, in: Digital Literacies: Concepts, Policies and Practices. New York: Peter Lang Publishing.

Hyun, D. L and Joon, H. L. (2014). A Study on Type of Smart city Grid Pipeline System (multiwaterloop system) and Application Method. International Journal of Control andAutomation (IJCA).

Keskin, N, O., Ozata, F, Z., dan Banar, K. (2015). Examining Digital Literacy Competences and Learning Habits of Open and Distance Learners. Contemporary Educational Technology. 6(1): 74-90

McLoughlin, C. (2011). What ICT-Related Skills and Capabilities Should be Considered Central to The Definition of Digital Literacy? Proceedings of World Conference on Educational Multimedia, Hypermedia and Telecommunications. Chesapeake. 471-475.

Murray, M.C. \& Perez, J. (2014). Unraveling The Digital Literacy Paradox: How Higher Education Fails At The Fourth Literacy, Issues In Informing Science And Technology, vol. 11, pp. 85-100

Santoso, A., dan Lestari, S. (2019).The Roles of Technology Literacy and Technology Integration to Improve Students' Teaching Competencies. KnE Social Sciences. 3(11): 243-256.

Sense, A. C. (2009). Digital Literacy and Citizenship in the 21st Century. San Francisco: Common Sense Media.

Shopova, T. (2014). Digital Literacy of Students and Its Improvement at the University. Journal of Efficiency and Responsibility in Education and Science. 7(2): 26-32. 